\title{
Effects of nest predation risk on female incubation behavior and offspring growth in great tits
}

\author{
Alessandra Basso ${ }^{1} \cdot$ Heinz Richner ${ }^{1}$ \\ Received: 30 October 2014 / Revised: 18 March 2015 / Accepted: 18 March 2015 / Published online: 2 April 2015 \\ (C) Springer-Verlag Berlin Heidelberg 2015
}

\begin{abstract}
Predation risk is a key driver for the evolution of reproductive strategies and life history traits. In birds, incubation behavior represents one form of parental care where trade-offs between time spent in incubation activities and self-maintenance activities are likely to change in response to predator pressure. This can have strong effects on embryonic development, but is still poorly understood. We investigated the effects of the presence of a nest predator on great tit (Parus major) incubation behavior and the subsequent effects of incubation on nestling morphological traits. We manipulated perceived predation risk using models of short-tailed weasels (Mustela erminea) in combination with great tit alarm calls specific to this predator. Directly after hatching, we swapped whole broods from treated nests with broods from untreated nests to disentangle treatment effects acting during the incubation period from potential carry-over effects on parental care acting on nestlings after hatching. In increased predation risk environments, the number of incubation sessions and recesses, but not their duration, was increased compared to the control group, and the nocturnal incubation session was longer when females were exposed to a predator. Eggs incubated by females under increased predation risk lost more mass over the incubation period compared to the control
\end{abstract}

Communicated by M. Leonard

Electronic supplementary material The online version of this article (doi:10.1007/s00265-015-1910-4) contains supplementary material, which is available to authorized users.

Alessandra Basso

alessandra.basso@iee.unibe.ch

Heinz Richner

heinz.richner@iee.unibe.ch

1 Evolutionary Ecology Lab, Institute of Ecology and Evolution, University of Bern, Baltzerstrasse 6, 3012 Bern, Switzerland group. Also, male nestlings hatched from nests exposed to predators were lighter at hatching but were equivalent in weight to their control counterparts at fledging. This suggests that nest predation risk can influence some aspects of incubation rhythm and embryonic development, but has no longterm effects on nestling final body size.

Keywords Incubation rhythm $\cdot$ Nest attentiveness $\cdot$ Nestling development $\cdot$ Parental care

\section{Introduction}

Predation is considered the most important cause of breeding failure in many bird species (Martin 1995; Silverin 1998). In altricial species, nest predation may affect both the evolution of parental care and life-history traits of offspring (Fontaine and Martin 2006; Martin and Briskie 2009). To reduce the consequences of predation risk, birds have evolved behavioral (Lima 1998; Conway and Martin 2000a; Ghalambor and Martin 2002; Kovarik and Pavel 2011) and physiological responses (Peluc et al. 2008; Hawlena and Schmitz 2010; Travers et al. 2010). Parental responses to predation pressure, such as choice of a concealed nesting site (Nilsson 1984), active and passive defence of the nest (Montgomerie and Weatherhead 1988; Eggers et al. 2005), altered incubation behavior (Deeming 2002; Zanette et al. 2011) and posthatching parental care (Ghalambor et al. 2013) can have a strong impact on offspring fitness (Lima 2009; Nord and Nilsson 2011). However, increased energy and time investment as a result of parental responses to predation may affect life-history trade-offs and reduce the parents' future reproductive value (Angelier and Chastel 2009).

Incubation behavior can be seen as a form of parental care that may induce trade-offs between time spent in incubation 
and self-maintenance activities in response to predator pressure (Ghalambor and Martin 2002; Ibáñez-Álamo and Soler 2012). However, the effects of increased predation risk on incubation behavior and, consequently, on nestling fitness after hatching have been neglected to a large extent (Rastogi et al. 2006; Nord and Nilsson 2012; DuRant et al. 2013). In particular, the effects of predation risk on incubation behavior were generally not separated from carry-over effects on parental care after hatching (e.g., Sanz 1997; Hanssen et al. 2005). Incubation behavior under changing predation risk can be flexible (Lima 2009), and the observed variation in incubation behaviors under such stressful conditions can provide important insight into parental decisions and effects on nestling development. For instance, trips from and to the nest can be reduced (e.g., less frequent incubation sessions and recesses) to avoid drawing a predator's attention to the nest (Conway and Martin 2000b; Smith et al. 2012). Altered parental behavior in response to increased predation risk can also later affect nestling development and quality (Lima 2009; Ardia et al. 2010; Sheriff et al. 2010). For example, an increase in predation risk can induce higher nest attendance (i.e., the amount of time the nest is attended by the incubating bird; Conway and Martin 2000a; Ghalambor and Martin 2002; Kovarik and Pavel 2011), shorten the length of the incubation period (i.e., the time between the onset of incubation and the hatching; Nord and Nilsson 2012), and can speed up physiological maturation of embryos and nestlings and time to fledging, in order to allow earlier departure from the nest (Martin and Briskie 2009; Cheng and Martin 2012).

In this study, we experimentally investigated the effects of nest predation risk on great tits (Parus major) during incubation and, subsequently, examined the effects of changes in incubation behavior on nestling development. To separate the effects of higher predation risk treatment during incubation from a confounding carry-over effect on parental care after hatching, we placed all nestlings after hatching into foster nests that had not experienced any treatment. To increase perceived risk of nest predation during incubation, we presented models of short-tailed weasels (Mustela erminea) and, as a control, used models of the European hedgehog (Erinaceus europaeus) in close vicinity to the nest, which does not predate great tit nests. Under higher predation risk, we expected females (1) to take longer and less frequent off-bouts (i.e., the periods during incubation in which the incubating bird is away from the nest) to minimize activity at the nest site and engage in self-maintenance behaviors, and (2) to increase incubation constancy (i.e., the total time spent in the nest each day, as a measure of nest attendance and incubation investment). Because faster embryonic development can reduce the risk of nest predation (Bosque and Bosque 1995; Remes and Martin 2002), we also predicted that (3) females under predation risk would maintain optimum incubation temperatures in order to shorten the incubation period (Martin et al. 2007;
Nord and Nilsson 2011). With regard to offspring quality and phenotype, we expected that (4) offspring of mothers under increased predation risk during incubation, brought up by foster parents, would leave the nest at smaller size and fledge earlier (Cheng and Martin 2012).

\section{Materials and methods}

\section{Study species}

The great tit is a small passerine that nests in natural holes, crevices, and nest boxes. Incubation is carried out solely by the female, while males may assist by providing food at the nest. Incubation behavior comprises incubation sessions where females sit on and warm the eggs, and off-bouts where females are away from the nest engaging in self-maintenance behaviors, and eggs cool down. During incubation sessions, females also perform nest sanitation activities and repeatedly turn the eggs (a common behavior, used probably to promote metabolization of the albumen and to guarantee normal embryo development) (Deeming 2002). Incubation lasts approximately 12 days, and its total duration is referred to as incubation period. Clutch size usually ranges from 5 to 12 eggs and offspring typically leave the nest 18-21 days after hatching (Gosler 1993).

\section{Study area}

The study was performed from mid-March to mid-June 2012 in the Bremgartenwald forest near Bern, Switzerland ( $46^{\circ} 57^{\prime}$ $\mathrm{N}, 7^{\circ} 24^{\prime} \mathrm{E}$ ). The area consists of approximately 600 ha of mainly deciduous trees (European beech Fagus sylvatica and few oaks Quercus spp.), and holds around 300 nest boxes (approximately $15 \times 15 \times 30 \mathrm{~cm}$, entrance hole $4-\mathrm{cm}$ diameter, mostly oriented south/southeast) distributed over 20 experimental plots (about $500 \times 300 \mathrm{~m}$ each). Plots are separated from each other by ca. $120 \mathrm{~m}$, corresponding to about two great tit territories (Olioso 2004), in order to reduce the influence of a given treatment on the neighbouring plot.

\section{General field procedures}

From mid-March onwards, nest boxes were visited regularly to determine clutch initiation, onset of incubation, clutch size, hatch day (day 0 ), and brood size. From day 16 posthatching, nests were checked daily in the late afternoon to determine fledging date and the number of fledged nestlings.

\section{Predator treatment}

We increased perceived predation risk in five experimental plots and assigned five plots to the control treatment. The remaining ten plots remained untreated (referred to as foster 
plots). Plots were allocated to the treatments once the first nest in the plot reached the second day of full incubation (to ascertain that incubation actually started). To allocate plots to treatments, we randomly created five blocks, each containing all four types of plots, i.e., one plot with the predator treatment, one with the control, and two untreated plots that were later used as foster plots. The order within blocks was determined randomly in advance. Once at least one nest reached the second day of full incubation, the whole plot was assigned to the first treatment in the first block, the second plot to the second treatment, etc. In case that more than one nest reached the predefined threshold on the same day, we rolled a dice to decide the order of assignment to one of the treatments (for details on the block randomization procedure, see Coslovsky and Richner 2011). The treatment was performed at the nest level, but all the nests in one plot received the same treatment in order to avoid the influence of the treatment on the neighbouring plots (see Online Resource 1 for experimental timeline). To increase perceived predation risk, we simulated the presence of a nest predator by using taxidermy mounts of short-tailed weasels placed on a branch below each nest box (approximately $1.5 \mathrm{~m}$ from the nest), close to the ground. In control plots, we used taxidermy mounts of European hedgehogs placed on the ground underneath the nest boxes. The position makes the manipulation more realistic by reflecting the hunting strategies of these animals. The short-tailed weasel is one of the main nest predators of great tits (Perrins 1965), active both during the day and during the night. Weasels can enter nest boxes (Korpimäki et al. 1991) and may either predate adults, eggs, or nestlings (Perrins 1979; Silverin 1998), while the European hedgehog does not present a threat for great tits and their eggs (being a potential risk only for eggs of ground-nesting birds; Dickman 1988). Both species occur naturally at the study site (AB, personal observation).

We placed the taxidermy mounts for 10 min every other day from the second day of full incubation until the hatching day. Predators were presented on alternate days to prevent habituation to the model (Silverin 1998; Pitk et al. 2012), and we used 10 min for the simulations because Coslovsky and Richner (2012) showed that $10 \mathrm{~min}$ of predator simulations every second day after hatching affected nestling growth and, therefore, was suitable for inducing a response in great tits.

We accompanied models with predator specific great tit calls. Great tit calls were recorded at the beginning of the breeding seasons by exposing four nests (excluded from the experiment) to the presence of the weasel models and recording great tit predator-specific calls. The same protocol was used in four nests to record background forest sounds when a hedgehog was presented, since no alarm calling was observed. Alarm and background calls were played back to experimental birds during weasel and hedgehog exposure, using portable loudspeakers (Fox-Pro NX3 game caller; FOXPRO Wildlife Equipment, Lewistown, PA, USA) positioned $2.5 \mathrm{~m}$ (range 2-3 m) away from the nest in a concealed position. Eight short-tailed weasel and eight European hedgehog models were used, alongside the four soundtracks recorded for each treatment. Models, soundtracks, and timing (either in the morning or in the afternoon) of simulation were constantly and randomly changed to prevent habituation to a specific model, call, or time.

\section{Clutch mass, incubation behavior, and incubation temperature}

On the third and tenth day of full incubation, whole clutches from predator and control treatment were weighed to the nearest $0.1 \mathrm{~g}$ using a portable electronic scale. During the measurement, eggs were carefully stored in small cottonpadded boxes and kept warm. The entrance hole of the nest box was blocked to prevent females from potentially deserting the nest after encountering an empty nest box, even for a short period. On the third day, we started recording female incubation behavior with small data loggers (Voltcraft DL-111 K; CONRAD, Electronic AG, Hirschau, Bayern, Germany) connected to a copper-constantan thermo probe. Nest material was carefully lifted from the bottom of the nest box without removing it from the nest box, and data loggers were placed underneath the nest material, at the bottom of the nest box. Probes were placed in the center of the nest cup at level with its lining with the eggs aggregated around it. The data logger recorded temperature changes in the nest-cup with a resolution of $0.1{ }^{\circ} \mathrm{C}$ every $20 \mathrm{~s}$ during the incubation period. Data loggers were calibrated by testing them at 5 and $25^{\circ} \mathrm{C}$ prior to use and recorded over $10 \mathrm{~min}$ every $30 \mathrm{~s}$. All data loggers appeared to be highly accurate $\left(N=50\right.$, mean $\pm 1 \mathrm{SD}$ : for $5{ }^{\circ} \mathrm{C}=5.3 \pm 0.20$; for $25^{\circ} \mathrm{C}=25.3{ }^{\circ} \mathrm{C} \pm 0.18$ ).

To verify that nest temperature fluctuations recorded by the data logger corresponded to incubation sessions and off-bouts, we placed a digital infrared camcorder (SONY HDRCX550VE) on the inside roof of each nest box on day 3 of incubation to monitor the behavior of incubating females (Martin et al. 2007; Wang and Beissinger 2009; Nord and Nilsson 2012) and the food provisioning behavior of the males to the incubating female. To minimize disturbance associated with installing a camcorder in the nest, a sticker of a dummy camera lens was fitted in each nest at the beginning of the breeding season. The first half hour of each video was discarded from the analyses. Camera recordings started at $0700 \mathrm{~h}$ in the morning and continued for 6 to $7 \mathrm{~h}$.

We analyzed all video recordings and compared them with the incubation profiles derived from the temperature loggers. This allowed to determine a sensible criterion for incubation off-bouts, which was best represented by a change of at least $2{ }^{\circ} \mathrm{C}$ in logged temperature occurring for a minimum of $4 \mathrm{~min}$ (two examples of incubation profiles are provided in the Online Resource 2). Changes in temperature were easily 
detectable when females left or returned to the nest and started a new incubation session (as assessed by comparing thermal data and video footage). However, as we measured temperatures at the base of the nest cup, it is likely that our estimate is rather conservative and slightly lower than egg temperature. We used these temperature records to analyze female incubation rhythms (i.e., length and temporal pattern of the incubation bouts) rather than absolute incubation temperatures of eggs, using the software combination of Raven version 1.4 and Rhythm 1.0 (Cooper and Mills 2005; Nord and Nilsson 2012). All program output files were checked for erroneous selections and, if necessary, corrected, although only minor adjustments on erroneous selections were required (e.g., cases in which a sharp drop in temperature lasted slightly less than $4 \mathrm{~min}$ ). Incubation behavior was analyzed for three incubation stages during two consecutive days (i) at the beginning of the incubation period on days $4-5$, (ii) in the middle of the incubation period on days 7-8, and (iii) in the end of the incubation period on days 9-10. We evaluated several variables characterising incubation behavior of the females: incubation temperature (average temperature detected across incubation sessions and off-bouts on each day), incubation constancy (the total amount of time the female spent inside the nest on each active day), average duration and number of off-bouts, average duration and number of incubation sessions (average time spent incubating on each day), length of the nocturnal incubation bout (calculated as the time between the end of the last and the start of the first off-bout on each day), and male incubation feeding (number of times the male fed the female during $5 \mathrm{~h}$ of video recording).

Ambient temperature and daily precipitation were derived from the Bundesamt für Umwelt (BAFU, Switzerland) NABEL weather station, located $3 \mathrm{~km}$ from the study site, and are reported as daily averages for each nest from the morning of the third incubation day until the day the probe was removed (day 10).

\section{Brood swapping}

One day after the first egg hatched whole broods of similar size ( \pm 1 nestling) and similar hatching date ( \pm 1 day) of the nests exposed to either predator or control treatment were swapped with broods from foster nests. Nestlings were transported and kept warm in small cotton-padded boxes. As an essential part of addressing our main question, swapping whole broods allowed us to disentangle later treatment effects acting during the incubation period from potential carry-over effects of parental behavior acting on nestling phenotype.

\section{Nestling growth}

Nestlings from treatment broods that were transferred to foster nests were weighed to the nearest $0.1 \mathrm{~g}$ using a portable electronic scale and individually marked by selectively removing tuft feathers before cross-fostering. This allowed individual identification until nestlings were old enough to be permanently ringed (on day 8 posthatch). On days 8 and 15 after hatching, body mass (to $0.1 \mathrm{~g}$ ), wing (to $0.5 \mathrm{~mm}$ ), and tarsus length (to $0.5 \mathrm{~mm}$ ) were measured (with a portable electronic scale, a ruler and a calliper, respectively). On day 8 , a small blood sample (less than $5 \mu \mathrm{l},<1 \%$ of the body mass) was collected from the nestling's meta-tarsal vein and stored in ethanol $96 \%$ for molecular sexing. Nestlings were sexed using the sexing primers 2917/3088 (Ellegren 1996).

\section{Statistical analysis}

Statistical analysis was performed using R 2.15.1 (R Development Core Team). Changes in incubation rhythm as incubation progressed were tested by examining incubation behavior during early (days 4-5), middle (days 7-8), and late incubation (days 9-10). Having performed three repeated observations from individual nests, we used stage of incubation as the repeated measure for each nest and nest identity nested in plot as random factors. We used linear mixed-effect models (LMM) with restricted maximum likelihood (REML) to assess treatment effects on all measurements related to incubation behavior (incubation temperature, incubation constancy, average off-bout duration, average duration of incubation sessions, and length of nocturnal incubation), mean egg mass per clutch at the beginning (day 3 ) and at the end (day 10) of the incubation, duration of incubation period, brood size at hatch, and fledging age. The response variable "average off-bout duration" was log-transformed to fit the assumptions of residual normality and homoscedasticity. In the tables, we provide log-transformed estimates.

Generalized linear mixed models (GLMM; R package lme4; Bates et al. 2011) with binomial error structure were used to assess the fledging success, calculated as the proportion of hatchlings that fledged from each nest. GLMM with Poisson error distribution were used to assess the effects of the treatment on the number of off-bouts and on the number of incubation sessions. A zero-inflated Poisson model was used to analyze male incubation feeding since $53.3 \%$ of males never performed observable incubation feeding during the recorded time. For GLMMs, significance was tested via likelihood ratio tests of nested models (Bolker et al. 2009). In models of incubation behavior, we included the two-way interaction between treatment and stage of incubation, and entered as covariates laying date, clutch size, average ambient temperature, and average daily precipitation. Plot of origin was included as a random effect in all models.

LMMs were also used to examine the effects of the treatment on nestling morphological measurements (mass on days 1,8 , and 15 , wing and tarsus on days 8 and 15). We included the two-way interaction between sex and treatment and 
included brood size and hatching date as covariates. Since two different people performed wing and tarsus measurements, we controlled for observer identity in wing and tarsus models. Nest of origin (nested within plot) was included as a random factor to control for genetic and environmental correlations between nestlings. In the analyses of nestling morphological traits, brood size and hatching date were centered on their mean. In the models related to incubation behavior, laying date, clutch size, average precipitation, and average ambient temperature were centered on their means.

Nonsignificant interactions (with $P>0.1$ ) were removed to improve interpretability of main effects (Engqvist 2005). Main effects, including covariates and treatments, were never eliminated from the model. To interpret significant interactions, models were stratified by treatment level and the model summaries were examined. Unless mentioned otherwise, means and standard errors are reported. Initial models are reported in the tables, and in the text, the results only of the best fitting models are given.

\section{Results}

The breeding birds never showed a response to the hedgehog models, but clearly recognized the weasel models as a threat since both parents gave alarm calls in $75 \%$ of all the exposure events and responded with aggressive behavior, such as hissing and mobbing in $79 \%$ of these cases.

Visual inspection on day 10, when the probe was removed, confirmed that it had not been displaced throughout the experiment in all but 11 cases (see below). Data for the whole incubation period was analyzed in 23 nests under the predator treatment and 21 nests under the control treatment, but 11 nests (predator treatment: $N=6$; control treatment: $N=5$ ) were excluded from subsequent analyses due to nest desertion or displacement of the probe. 73 pairs of nests were successfully swapped, and in 33 of them, the incubation patterns had been previously recorded, as mentioned above.

\section{Incubation behavior}

Off-bout duration recorded by data loggers were not significantly different from video analyses (paired $t$ test: $\Delta_{\text {off-bouts }}=$ $\left.23.77 \mathrm{~s} \pm 35.77 \mathrm{~s} ; t_{42}=1.34 ; P=0.187\right)$.

Average daily incubation temperature did not differ significantly among treatment groups $\left(F_{1,8}=0.043, P=0.840\right)$. Predator treatment did not significantly influence incubation constancy (i.e., total time spent inside the nest each day: $449.617 \pm 10.773 \mathrm{~min}$ under control treatment vs. $438.85 \pm$ 10.338 min under predator treatment; $F_{1,8}=0.904, P=$ $0.369)$. The length of the off-bouts was not significantly influenced by the treatment $(8.694 \pm 1.071 \mathrm{~min}$ under control treatment vs. $8.764 \pm 1.068 \mathrm{~min}$ under predator treatment; $F_{1}$, $\left.{ }_{8}=0.006, P=0.940\right)$, but females under increased predation risk had a significantly higher number of off-bouts $(24.475 \pm$ $1.056 /$ day) than those in the control group $(20.749 \pm 1.058 /$ day; $\chi_{1}^{2}=5.479, P=0.019$; Fig. 1). Treatment did not affect the length of incubation sessions $(10.710 \pm 0.854$ min under control treatment vs. $9.338 \pm 0.839$ min under predator treatment; $F_{1,8}=1.213, P=0.303$ ), but the number of incubation sessions was higher when females were exposed to the presence of a nest predator $33.032( \pm 1.071)$ /day under predator treatment vs. $27.144( \pm 1.074) /$ day under control treatment $\left(\chi_{1}^{2}=3.900, P=0.048\right.$; Fig. 1$)$. Females in increased predation risk environments spent $20.5 \mathrm{~min} \pm 9.1 \mathrm{~min}$ longer incubating during the night compared to females in the control group $\left(F_{1}\right.$, ${ }_{27}=5.103, P=0.032$; Fig. 2). However, duration of incubation did not differ between treatment and control groups $\left(F_{1,8}=\right.$ 2.949, $P=0.124)$, but decreased with higher ambient temperatures $\left(F_{1,75}=4.085, P=0.047\right)$.

For the detailed tables of estimates $( \pm \mathrm{SE})$ of incubation behavior, see Table 1 .

\section{Other incubation parameters}

Incubation feeding (number of times the male fed the female) was not significantly influenced by the predator treatment $(0.482 \pm 1.704$ under predator treatment vs. $1.163 \pm 1.379$ under control treatment, $z=-1.417, P=0.157)$. Egg mass at the beginning of incubation (day 3 ), was not significantly affected by the treatment $(12.408 \pm 0.447 \mathrm{~g}$ under predator treatment vs. $11.723 \pm 0.531 \mathrm{~g}$ under control treatment, $F_{1,8}=0.967, P=$ 0.354). Eggs of females incubating in the predator treatment lost more mass during the incubation period than those of

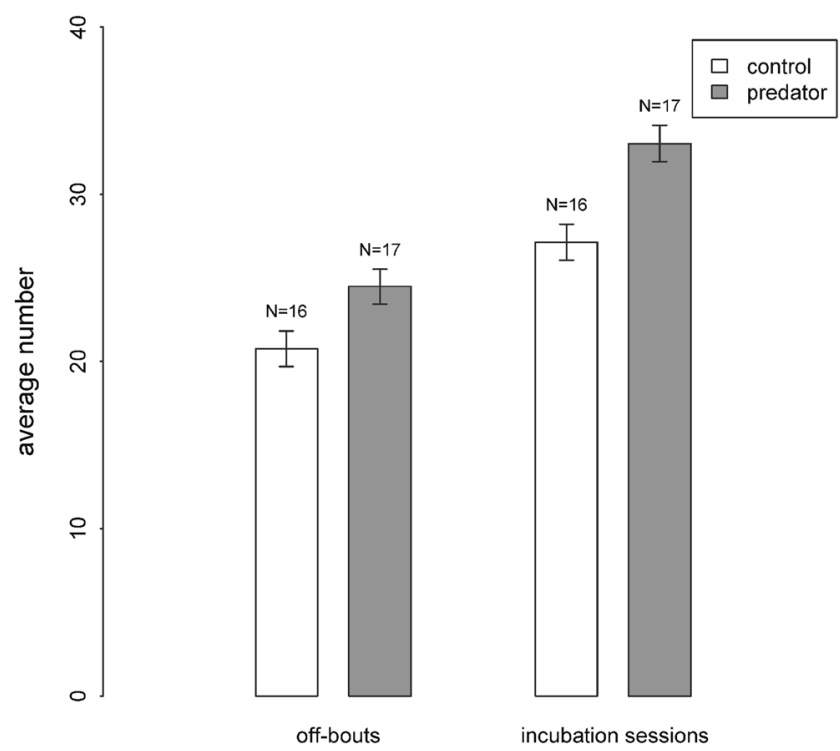

Fig. 1 Average number of off-bouts and incubation sessions (mean $\pm \mathrm{SE}$ ) from a GLMM with Poisson error structure. Females incubating in increased predation risk environments had a higher number of offbouts/day and of incubation sessions/day compared to the control group (off-bouts: $P=0.019$; incubation sessions: $P=0.048$ ) 


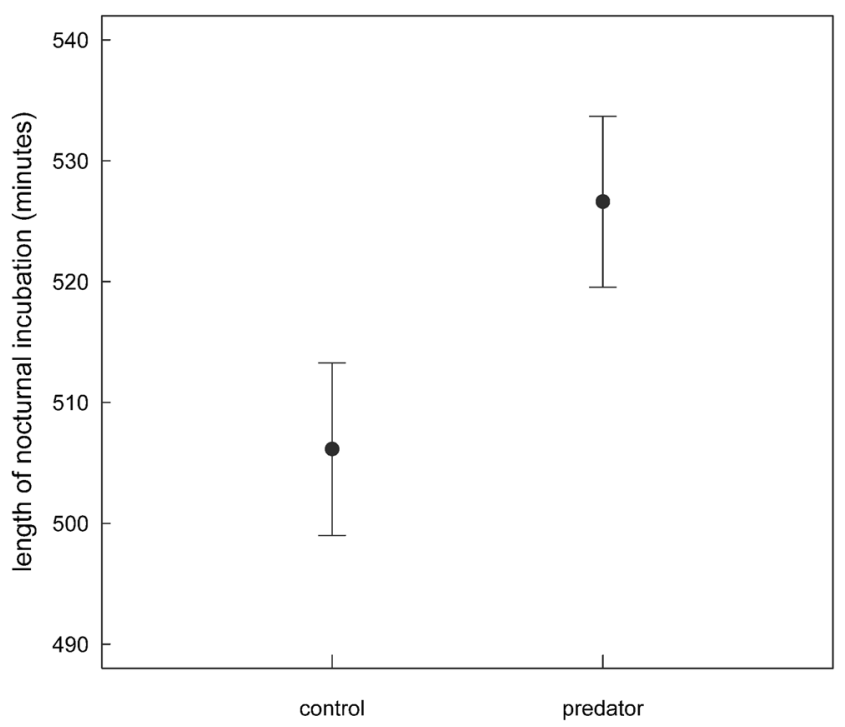

Fig. 2 Average length of nocturnal incubation (time between the end of the last and the start of the first off-bout on each day). Females incubating in increased predation risk environments spent more time in the nest during the night compared to females in the control group $(P=0.032)$

control females, as assessed at the end of the incubation (day 10) $-0.323 \pm 0.178 \mathrm{~g}$ lost under predator treatment vs. -0.151 $\pm 0.162 \mathrm{~g}$ lost under control treatment $\left(F_{1,8}=5.451, P=0.048\right)$. Brood size was not related to the treatment $\left(F_{1,8}=0.300, P=\right.$ $0.599)$, but it was smaller under higher levels of precipitation $\left(F_{1,63}=12.546, P<0.001\right)$.

\section{Nestling phenotype}

Results (with estimates $\pm \mathrm{SE}$ ) of models for morphological measures and growth are given in Table 2 . We found a significant sex-dependent effect of the predator treatment on nestling mass on the first day after hatching (interaction $\operatorname{sex} \times$ treatment: $\left.F_{1,306}=6.622, P=0.010\right)$. Male nestlings of mothers exposed to an increased risk of predation were significantly lighter than their female siblings (Fig. 3). Moreover, males from the increased predation risk group were significantly lighter than males of the control group, while there was no effect on females (Fig. 3). Differences in mass between treatment groups were no longer visible both on day $8(10.690 \pm$ $0.246 \mathrm{~g}$ under predator treatment vs. $10.595 \pm 0.281 \mathrm{~g}$ under control treatment, $\left.F_{1,66}=0.073, P=0.788\right)$ and on day 15 $(15.388 \pm 0.302 \mathrm{~g}$ under predator treatment vs. $15.026 \pm$ $0.344 \mathrm{~g}$ under control treatment, $F_{1,54}=0.689, P=0.410$ ). Treatment did not affect wing or tarsus length both of 8 - and 15-day-old nestlings. Fledging age correlated positively and fledging success negatively with brood size [fledging age: $0.217 \pm 0.073, F_{1,50}=8.884$; fledging success: $-0.232 \pm 0.076$ (estimate $\pm \mathrm{SE}$ ); both $P$ values $<0.005$ ], but were not significantly different among treatments (fledging age: $18.449 \pm$ 0.515 days under predator treatment vs. $18.828 \pm 0.483$ days under control treatment, $F_{1,8}=1.797, P=0.217$; fledging success: $99.3 \%$ under predator treatment vs. $99.4 \%$ under control treatment, $P=0.799$ ).

We report, in Table 3, a list of all the metrics obtained for all incubation parameters and nestling phenotype for each treatment group.

\section{Discussion}

The aim of this experiment was to test whether increased nest predation risk during incubation affected female incubation patterns and, subsequently, reproductive performance. We predicted that in the presence of a nest predator females would reduce activity at the nest, with longer, less frequent off-bouts, and increase incubation constancy. However, the number of off-bouts and incubation sessions was higher when mothers were exposed to the presence of a nest predator. This result is in contrast with previous findings, where the number of movements to and from the nest during incubation was reduced in the presence of a predator (Martin and Ghalambor 1999; Conway and Martin 2000b; Martin et al. 2000; Ibáñez-Álamo and Soler 2012).

The higher number of off-bouts and, consequently, of incubation sessions found in our study may entail higher costs of incubation for the female, as it implies a higher number of times females must rewarm the clutch (Jones 1989; Conway and Martin 2000b) and an increase in visual cues for predators. However, an increased number of off-bouts would not necessarily lead to higher costs of rewarming the clutch if the length of these off-bouts was short enough to avoid a significant drop in egg temperature. Besides, a higher number of incubation sessions should intuitively imply an increased amount of time spent incubating during the day. However, analyses of incubation constancy, duration of off-bouts, and incubation sessions did not reveal significant differences between predator and control treatment, making it difficult to identify a clear cause for the observed pattern.

One possible reason for the discrepancy between studies may be that cavity-nesting birds respond differently than open-nesting birds, as they may not be able to visually detect a potential threat and may put more emphasis on leaving the nest cavity to escape predation. Females nesting in artificial nest boxes may be particularly sensitive to this risk because of the size of the entrance hole and the conspicuousness of the nest. Alternatively, the type of response found in our study might partly depend on male incubation feeding effort. It has been shown that males may reduce provisioning efforts to incubating females under increased predation risk, thus forcing females to leave the nest box more frequently to forage (Martin and Ghalambor 1999). Although our analysis did not show a significant effect of the predator treatment on male incubation feeding, we cannot exclude a potential effect of the increased predation risk on male feeding effort, since the recordings were made only at the beginning of the incubation 


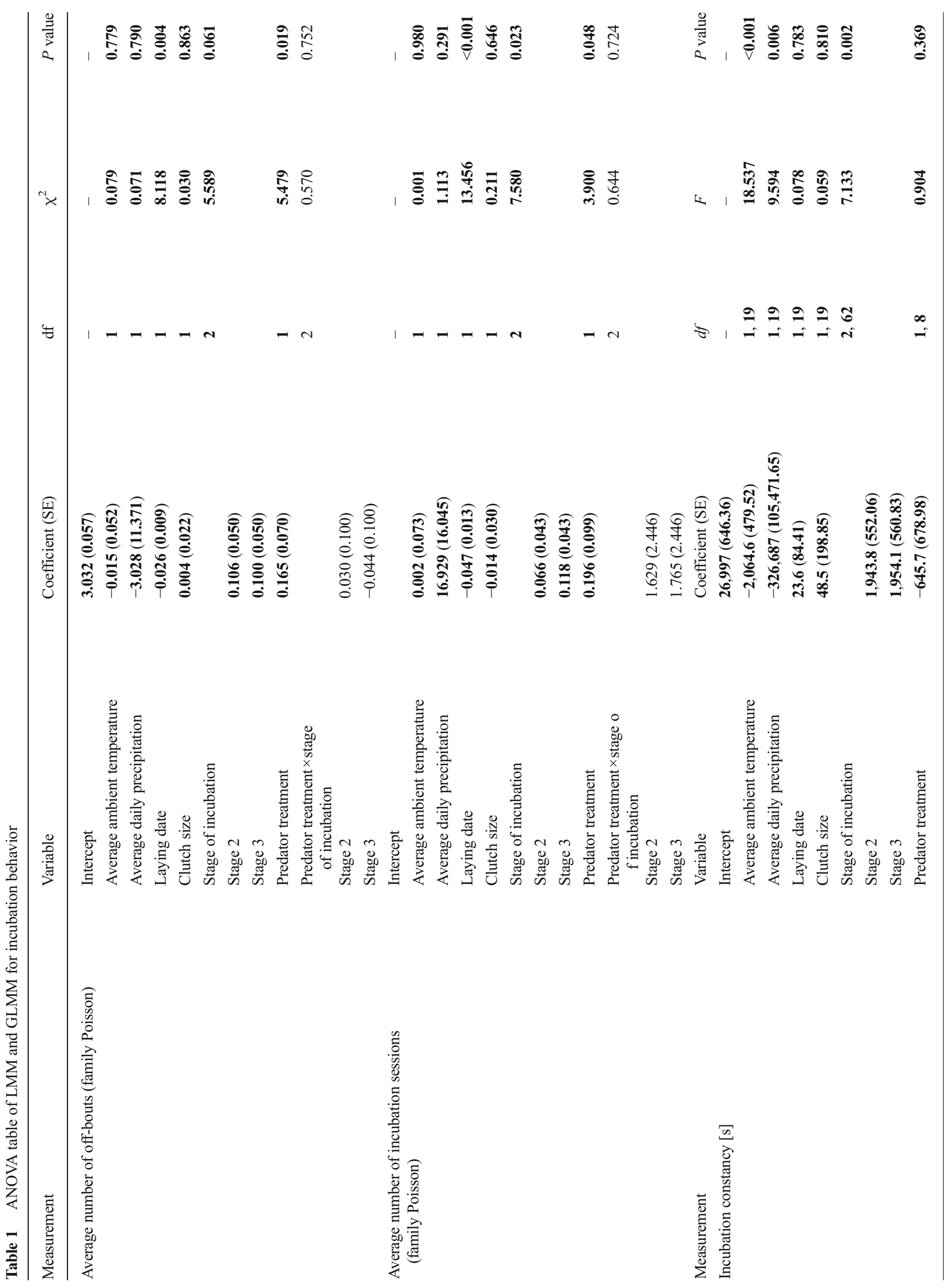




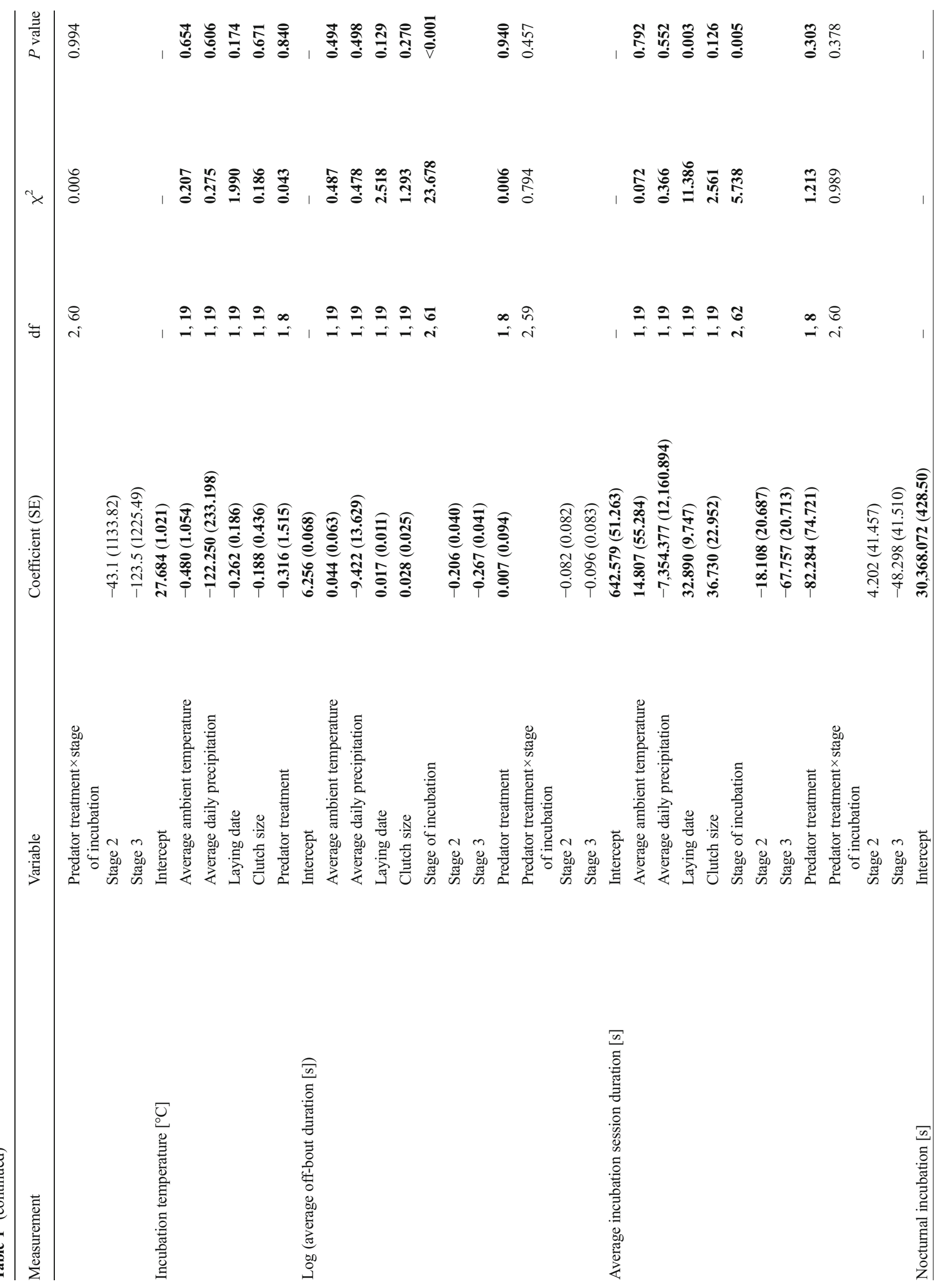




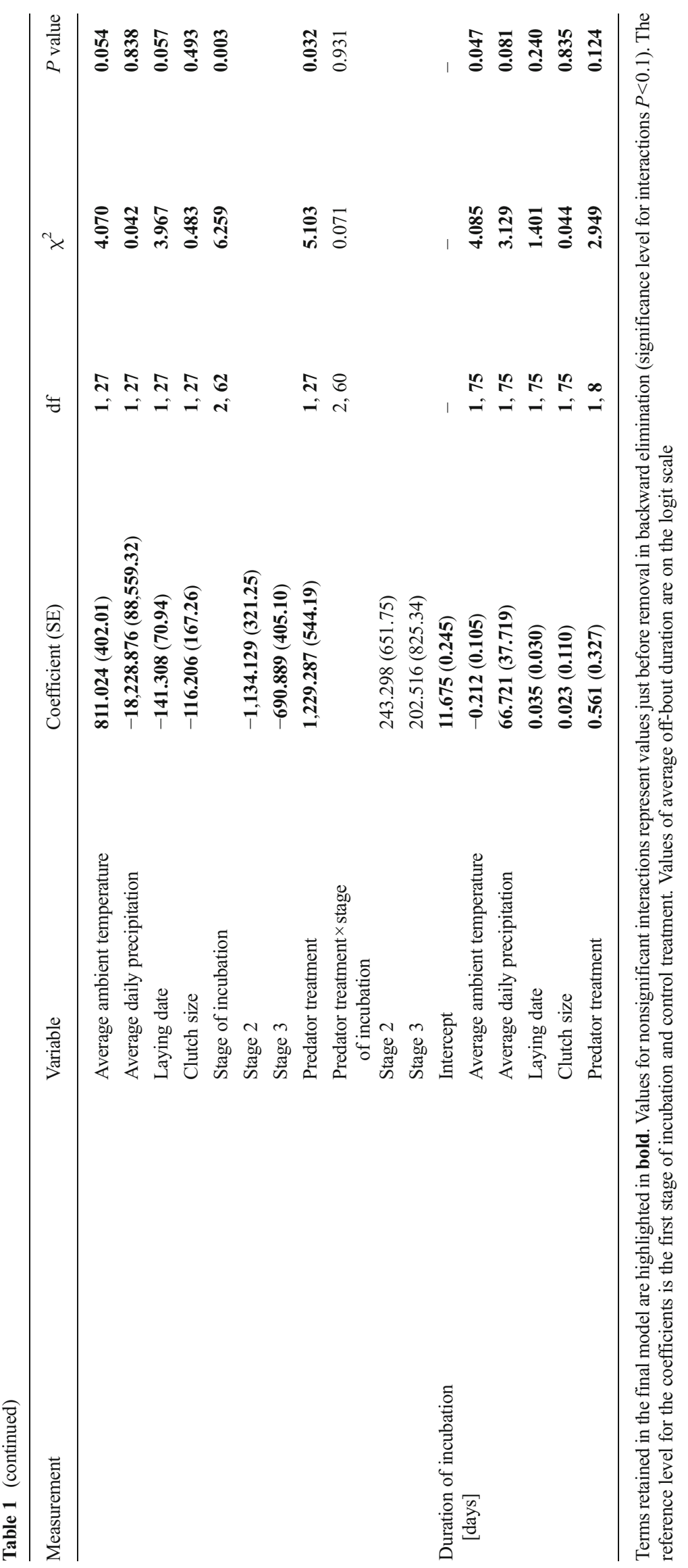


Table 2 ANOVA table of LMM for nestling morphological measures and growth

\begin{tabular}{|c|c|c|c|c|c|}
\hline Measurement & Variable & Coefficient (SE) & $d f$ & $\mathrm{~F}$ & $P$ value \\
\hline \multirow[t]{6}{*}{ Mass day $1[\mathrm{~g}]$} & Intercept & $1.813(0.064)$ & - & - & - \\
\hline & Brood size & $-0.035(0.017)$ & 1,53 & 3.971 & 0.051 \\
\hline & Hatching date & $-0.010(0.005)$ & 1,53 & 3.324 & 0.074 \\
\hline & Sex & $0.044(0.040)$ & 1,306 & 1.183 & 0.278 \\
\hline & Predator treatment & $-0.063(0.065)$ & 1,53 & 0.941 & 0.336 \\
\hline & Predator treatment $\times$ sex & $-0.140(0.054)$ & 1,306 & 6.622 & 0.010 \\
\hline \multirow[t]{6}{*}{ Mass day $8[\mathrm{~g}]$} & Intercept & $10.595(0.281)$ & - & - & - \\
\hline & Brood size & $-0.309(0.112)$ & 1,66 & 7.600 & 0.007 \\
\hline & Hatching date & $-0.002(0.030)$ & 1,66 & 0.005 & 0.945 \\
\hline & Sex & $0.278(0.156)$ & 1,313 & 3.151 & 0.077 \\
\hline & Predator treatment & $0.094(0.350)$ & 1,66 & 0.073 & 0.788 \\
\hline & Predator treatment $\times$ sex & $-0.309(0.312)$ & 1,312 & 0.976 & 0.324 \\
\hline \multirow[t]{6}{*}{ Mass day 15 [g] } & Intercept & $15.026(0.344)$ & - & - & - \\
\hline & Brood size & $-0.538(0.132)$ & 1,54 & 16.710 & $<0.001$ \\
\hline & Hatching date & $-0.065(0.037)$ & 1,54 & 3.012 & 0.088 \\
\hline & Sex & $0.982(0.147)$ & 1,231 & 44.616 & $<\mathbf{0 . 0 0 1}$ \\
\hline & Predator treatment & $0.362(0.436)$ & 1,54 & 0.689 & 0.410 \\
\hline & Predator treatment $\times$ sex & $0.128(0.296)$ & 1,230 & 0.188 & 0.665 \\
\hline \multirow[t]{7}{*}{ Wing day 8 [mm] } & Intercept & $19.261(0.649)$ & - & - & - \\
\hline & Brood size & $-0.052(0.210)$ & 1,65 & 0.061 & 0.805 \\
\hline & Hatching date & $0.069(0.057)$ & 1,65 & 1.452 & 0.232 \\
\hline & Performer & $2.619(0.656)$ & 1,65 & 15.947 & $<\mathbf{0 . 0 0 1}$ \\
\hline & Sex & $-0.143(0.301)$ & 1,313 & 0.224 & 0.636 \\
\hline & Predator treatment & $-0.074(0.654)$ & 1,65 & 0.013 & 0.910 \\
\hline & Predator treatment $\times$ sex & $-0.504(0.612)$ & 1,312 & 0.679 & 0.410 \\
\hline \multirow[t]{7}{*}{ Wing day $15[\mathrm{~mm}]$} & Intercept & $45.135(1.043)$ & - & - & - \\
\hline & Brood size & $-0.601(0.297)$ & 1,53 & 4.104 & 0.048 \\
\hline & Hatching date & $-0.007(0.082)$ & 1,53 & 0.008 & 0.927 \\
\hline & Performer & $1.078(1.055)$ & 1,53 & 1.044 & 0.312 \\
\hline & Sex & $0.781(0.368)$ & 1,230 & 4.504 & 0.035 \\
\hline & Predator treatment & $0.432(0.912)$ & 1,53 & 0.224 & 0.638 \\
\hline & Predator treatment $\times$ sex & $0.159(0.742)$ & 1,229 & 0.046 & 0.831 \\
\hline \multirow[t]{7}{*}{ Tarsus day $8[\mathrm{~mm}]$} & Intercept & $14.838(0.238)$ & - & - & - \\
\hline & Brood size & $-0.002(0.078)$ & 1,65 & $<0.001$ & 0.981 \\
\hline & Hatching date & $0.005(0.021)$ & 1,65 & 0.052 & 0.819 \\
\hline & Performer & $0.792(0.245)$ & 1,65 & 10.437 & 0.002 \\
\hline & Sex & $0.058(0.109)$ & 1,311 & 0.281 & 0.596 \\
\hline & Predator treatment & $-0.022(0.244)$ & 1,65 & 0.008 & 0.929 \\
\hline & Predator treatment $\times$ sex & $-0.061(0.219)$ & 1,310 & 0.078 & 0.781 \\
\hline \multirow[t]{7}{*}{ Tarsus day $15[\mathrm{~mm}]$} & Intercept & $18.435(0.197)$ & - & - & - \\
\hline & Brood size & $-0.039(0.056)$ & 1,53 & 0.495 & 0.485 \\
\hline & Hatching date & $0.003(0.016)$ & 1,53 & $\mathbf{0 . 0 3 0}$ & 0.863 \\
\hline & Performer & $0.514(0.200)$ & 1,53 & 6.599 & 0.013 \\
\hline & Sex & $0.605(0.067)$ & 1,230 & 82.223 & $<\mathbf{0 . 0 0 1}$ \\
\hline & Predator treatment & $0.020(0.172)$ & 1,53 & 0.014 & 0.906 \\
\hline & Predator treatment $\times$ sex & $0.027(0.135)$ & 1,229 & 0.041 & 0.840 \\
\hline
\end{tabular}

Terms retained in the final model are highlighted in bold. Values for nonsignificant interactions represent values just before removal in backward elimination (significance level for interactions $P<0.1$ ). The reference level for the coefficients is a female nestling under control treatment 


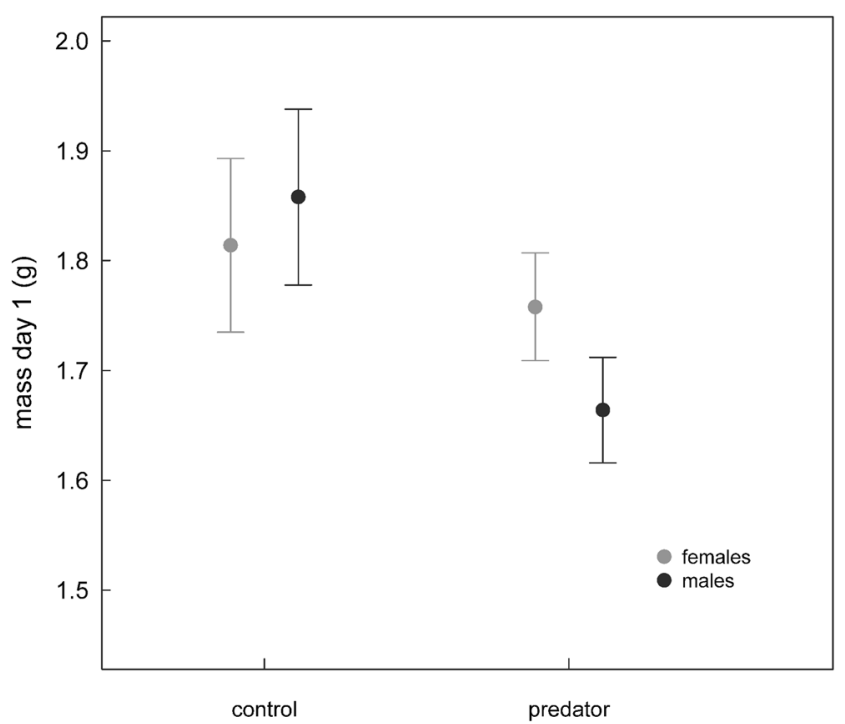

Fig. 3 Body mass on day 1 (mean \pm SE) of female and male nestlings. Males from the increased predation risk group were significantly lighter than males from the control group $(P=0.010)$. Male nestlings born from mothers exposed to an increased risk of predation were significantly lighter than females from this group $(P=0.010)$

period, and only inside the nest box: indeed, some males do not feed their mate in the nest box, but use a specific call to attract the female outside and feed her in the vicinity of the nest, or lead her to profitable foraging patches (Royama 1966; de Heij et al. 2006). Moreover, male alarm calls outside the nest in the presence of a predator close to the nest may have interrupted incubation sessions and thus possibly also explain why movements to and from the nest were more frequent for treatment compared to control groups.

We predicted that incubation temperatures would be higher under higher predation risk and that this would result in a shorter incubation period. However, neither of these variables significantly changed in response to predation risk. The lack of significant effects may be due to the fact that treatment effects were relatively small and statistical power was too weak. Besides, as mentioned previously, our estimate of incubation temperatures may be slightly lower than egg temperature and possibly made the detection of an effect of the treatment more difficult. A clear interpretation of female investment and incubation costs would require a strong link between the number of both off-bouts and incubation sessions with their duration, incubation constancy, and temperature.

Interestingly, females incubating under higher predation risk showed prolonged nocturnal incubation. If birds are more prone to being detected by predators during the nocturnal period, females may have limited the movements during the risky phase of dawn and dusk, even though such behavior may prolong incubation. However, considering that total incubation time covers around $80 \%$ of the whole day, an additional 20 min may have a negligible effect on embryo development.
Table 3 Metrics of all incubation parameters and nestling phenotype for each treatment group

\begin{tabular}{|c|c|c|}
\hline Measurement & Predator & Control \\
\hline Deserted nests & 8 & 10 \\
\hline Average incubation session duration [min] & 9.3 & 10.7 \\
\hline Average number of incubation sessions per day & 33.0 & 27.1 \\
\hline Average off-bout duration [min] & 8.8 & 8.7 \\
\hline Average number of off-bouts per day & 24.5 & 20.7 \\
\hline Incubation constancy [min] & 438.8 & 449.6 \\
\hline Nocturnal incubation [min] & 526.3 & 506.1 \\
\hline Incubation temperature $\left[{ }^{\circ} \mathrm{C}\right]$ & 27.7 & 27.4 \\
\hline Incubation feeding & 0.5 & 1.2 \\
\hline Duration of incubation [day] & 12.2 & 11.7 \\
\hline Egg mass day 3 of incubation [g] & 12.4 & 11.7 \\
\hline Egg mass loss during incubation $[\mathrm{g}]$ & 0.3 & 0.1 \\
\hline Nestling mass day $1[\mathrm{~g}]$ & 1.7 & 1.8 \\
\hline Nestling mass day $8[\mathrm{~g}]$ & 10.7 & 10.6 \\
\hline Nestling mass day $15[\mathrm{~g}]$ & 15.4 & 15.0 \\
\hline Nestling mass gain $[\mathrm{g}]$ & 13.0 & 12.7 \\
\hline Nestling wing length day 8 [mm] & 19.2 & 19.3 \\
\hline Nestling wing length day $15[\mathrm{~mm}]$ & 45.6 & 45.1 \\
\hline Nestling tarsus length day $8[\mathrm{~mm}]$ & 14.8 & 14.8 \\
\hline Nestling tarsus length day $15[\mathrm{~mm}]$ & 18.5 & 18.4 \\
\hline Brood size & 6.1 & 5.9 \\
\hline Fledging age [day] & 18.4 & 18.8 \\
\hline Fledging success [\%] & 99.3 & 99.4 \\
\hline
\end{tabular}

Embryonic development was expected to be faster in nests where incubating females experienced increased predation risk, and offspring were predicted to leave the nest at a smaller size and show a shorter latency from hatching to fledging (Cheng and Martin 2012). In our study, the incubation patterns of females under increased predation pressure had indeed some implications for embryo development, but the effects on offspring seem to affect early stages of nestling life only. While we found no effect of our treatment on brood size, the eggs incubated by females in the predator treatment lost more weight compared to eggs incubated by females of the control group, possibly due to increased water loss induced by higher temperature fluctuations. Furthermore, the mass of male nestlings immediately after hatching was lower when the genetic mothers had been exposed to the predator treatment compared to the control group. The sex-specific effect found for body mass directly after hatching may imply possible mechanisms acting differentially on the two sexes during embryo development. One possible explanation is that male nestlings hatched a few hours later than females (although practically all nestlings hatched within $24 \mathrm{~h}$ after the first hatched egg), maybe due to a sex-specific effect of frequent cooling and temperature fluctuations. Alternatively, selection to speed up development shortly before hatching may act more strongly on female 
than on male nestlings. Under stressful conditions, females are often out-competed by males (Oddie 2000), and hatching some hours earlier may provide a competitive advantage in the earlier phases of growth. Indeed, embryos can perceive features of the acoustic environment shortly before hatching (e.g., Vince 1969; Schwagmeyer et al. 1991; ColombelliNégrel et al. 2014), thus potentially also perceive alarm calls, and could either speed up growth or hatch earlier. Without specific data on hatching asynchrony, these alternative scenarios remain speculative. There were no carry-over effects on nestling on days 8 and 15, fledging age, and fledging success. It is possible that nestlings from the predator treatment group begged more intensively than those from the controls, resulting in an increase in parental provisioning and therefore in growth rates. The effects of the incubation behavior seem to affect only early stages of nestling life, but possible effects on future survival and reproduction cannot be excluded.

In conclusion, our results show that incubating mothers are sensitive to nest predation risk. Predation risk seems to affect some aspects of female incubation behavior (i.e., number of off-bouts, incubation sessions, and night incubation) and, consequently, embryonic development. However, the assessment of the direction and the amplitude of female reproductive investment would need to be supported by significant differences on incubation temperature and nest attendance, for instance, thus the interpretation of the results is not straightforward and more studies on several species, potentially larger sample sizes and stronger predator risk, seem essential.

Acknowledgments We thank Henrietta Bellman, Sanne Ruyts, and Fabiano Sartirana for field assistance and Andreas Nord and Michael Coslovsky for useful comments on the manuscript. Taxidermic models were provided by Christian Schneiter (Arche de Noé, Viques). The work was funded by the Swiss National Science Foundation (grant 31003A 122566 to HR).

Ethical standards This work was conducted under license of the Ethical Committee of the Agricultural Office of the Canton Bern (BE22/11). Bird catching and ringing were performed with a permission of the Federal Agency for the Environment of the Canton of Bern, Switzerland (ringing permit 2992).

\section{References}

Angelier F, Chastel O (2009) Stress, prolactin and parental investment in birds: a review. Gen Comp Endocrinol 163:142-148

Ardia DR, Perez JH, Clotfelter ED (2010) Experimental cooling during incubation leads to reduced innate immunity and body condition in nestling tree swallows. Proc R Soc Lond B 277:1881-1888

Bates D, Maechler M, Bolker B (2011) lme4. Linear mixed-effects models using S4 classes R package version 0999375-34. http:// CRANR-projectorg $/$ package $=1 \mathrm{me} 4$

Bolker BM, Brooks ME, Clark CJ, Geange SW, Poulsen JR, Stevens MHH, White JSS (2009) Generalized linear mixed models: a practical guide for ecology and evolution. Trends Ecol Evol 24:127-135
Bosque C, Bosque MT (1995) Nest predation as a selective factor in the evolution of developmental rates in altricial birds. Am Nat 145:234 260

Cheng YR, Martin TE (2012) Nest predation risk and growth strategies of passerine species: grow fast or develop traits to escape risk? Am Nat 180:285-295

Colombelli-Négrel D, Hauber ME, Kleindorfer S (2014) Prenatal learning in an Australian songbird: habituation and individual discrimination in superb fairy-wren embryos. Proc R Soc B 281:20141154

Conway CJ, Martin TE (2000a) Effects of ambient temperature on avian incubation behavior. Behav Ecol 11:178-188

Conway CJ, Martin TE (2000b) Evolution of passerine incubation behavior: influence of food, temperature, and nest predation. Evolution 54: $670-685$

Cooper CB, Mills J (2005) New software for quantifying incubation behavior from time-series recordings. J Field Ornithol 76:352-356

Coslovsky M, Richner H (2011) Predation risk affects offspring growth via maternal effects. Funct Ecol 25:878-888

Coslovsky M, Richner H (2012) An experimental test of predator-parasite interaction in a passerine bird. Oikos 121:1691-1701

de Heij ME, van den Hout PJ, Tinbergen JM (2006) Fitness cost of incubation in great tits (Parus major) is related to clutch size. Proc R Soc Lond B 273:2353-2361

Deeming DC (2002) Avian incubation. Behaviour, environment, and evolution. Oxford University Press, Oxford

Dickman CR (1988) Age-related dietary change in the European hedgehog, Erinaceus europaeus. J Zool 215:1-14

DuRant SE, Hopkins WA, Hepp GR, Walters JR (2013) Ecological, evolutionary, and conservation implications of incubation temperaturedependent phenotypes in birds. Biol Rev Camb Philos Soc 88:499509

Eggers S, Griesser M, Ekman J (2005) Predator-induced plasticity in nest visitation rates in the Siberian jay (Perisoreus infaustus). Behav Ecol 16:309-315

Ellegren H (1996) First gene on the avian W chromosome (CHD) provides a tag for universal sexing of non-ratite birds. Proc R Soc Lond B 263:1635-1641

Engqvist L (2005) The mistreatment of covariate interaction terms in linear model analyses of behavioural and evolutionary ecology studies. Anim Behav 70:967-971

Fontaine JJ, Martin TE (2006) Parent birds assess nest predation risk and adjust their reproductive strategies. Ecol Lett 9:428-434

Ghalambor CK, Martin TE (2002) Comparative manipulation of predation risk in incubating birds reveals variability in the plasticity of responses. Behav Ecol 13:101-108

Ghalambor CK, Peluc SI, Martin TE (2013) Plasticity of parental care under the risk of predation: how much should parents reduce care? Biol Lett 9:20130154

Gosler A (1993) The great tit. Hamlyn, London

Hanssen SA, Hasselquist D, Folstad I, Erikstad KE (2005) Cost of reproduction in a long-lived bird: incubation effort reduces immune function and future reproduction. Proc R Soc Lond B 272:1039-1046

Hawlena D, Schmitz OJ (2010) Physiological stress as a fundamental mechanism linking predation to ecosystem functioning. Am Nat 176:537-556

Ibáñez-Álamo JD, Soler M (2012) Predator-induced female behavior in the absence of male incubation feeding: an experimental study. Behav Ecol Sociobiol 66:1067-1073

Jones G (1989) Optimizing time off the nest during incubation in female swallows (Hirundo rustica L.). Funct Ecol 3:303-309

Korpimäki E, Norrdahl K, Rintajaskari T (1991) Responses of stoats and least weasels to fluctuating food abundances - is the low phase of the vole cycle due to mustelid predation. Oecologia 88:552-561

Kovarik P, Pavel V (2011) Does threat to the nest affect incubation rhythm in a small passerine? Ethology 117:181-187 
Lima SL (1998) Nonlethal effects in the ecology of predator-prey interactions - what are the ecological effects of anti-predator decisionmaking? Bioscience 48:25-34

Lima SL (2009) Predators and the breeding bird: behavioral and reproductive flexibility under the risk of predation. Biol Rev Camb Philos Soc $84: 485-513$

Martin TE (1995) Avian life-history evolution in relation to nest sites, nest predation, and food. Ecol Monogr 65:101-127

Martin TE, Briskie JV (2009) Predation on dependent offspring: a review of the consequences for mean expression and phenotypic plasticity in avian life history traits. Ann NY Acad Sci 1168:201-217

Martin TE, Ghalambor CK (1999) Males feeding females during incubation: I. Required by microclimate or constrained by nest predation. Am Nat 153:131-139

Martin TE, Scott J, Menge C (2000) Nest predation increases with parental activity: separating nest site and parental activity effects. Proc R Soc Lond B 267:2287-2293

Martin TE, Auer SK, Bassar RD, Niklison AM, Lloyd P (2007) Geographic variation in avian incubation periods and parental influences on embryonic temperature. Evolution 61:2558-2569

Montgomerie RD, Weatherhead PJ (1988) Risks and rewards of nest defense by parent birds. Q Rev Biol 63:167-187

Nilsson SG (1984) The evolution of nest-site selection among holenesting birds - the importance of nest predation and competition. Ornis Scand 15:167-175

Nord A, Nilsson JA (2011) Incubation temperature affects growth and energy metabolism in blue tit nestlings. Am Nat 178:639-651

Nord A, Nilsson JA (2012) Context-dependent costs of incubation in the pied flycatcher. Anim Behav 84:427-436

Oddie KR (2000) Size matters: competition between male and female great tit offspring. J Anim Ecol 69:903-912

Olioso G (2004) Les mésanges. Les sentiers du naturaliste. Delachaux et Niestlé, Paris

Peluc SI, Sillett TS, Rotenberry JT, Ghalambor CK (2008) Adaptive phenotypic plasticity in an island songbird exposed to a novel predation risk. Behav Ecol 19:830-835

Perrins CM (1965) Population fluctuations and clutch-size in the great tit, Parus major L. J Anim Ecol 34:601-647
Perrins CM (1979) British tits. Collins, London

Pitk M, Tilgar V, Kilgas P, Mand R (2012) Acute stress affects the corticosterone level in bird eggs: a case study with great tits (Parus major). Horm Behav 62:475-479

Rastogi AD, Zanette L, Clinchy M (2006) Food availability affects diurnal nest predation and adult antipredator behaviour in song sparrows, Melospiza melodia. Anim Behav 72:933-940

Remes V, Martin TE (2002) Environmental influences on the evolution of growth and developmental rates in passerines. Evolution 56:25052518

Royama T (1966) Factors governing feeding rate, food requirement and brood size of nestling great tits Parus major. Ibis 108:313-347

Sanz JJ (1997) Clutch size manipulation in the pied flycatcher: effects on nestling growth, parental care and moult. J Avian Biol 28:157-162

Schwagmeyer P, Mock DW, Lamey TC, Beecher MD (1991) Effects of sibling contact on hatch timing in an asynchronously hatching bird. Anim Behav 41:887-894

Sheriff MJ, Krebs CJ, Boonstra R (2010) The ghosts of predators past: population cycles and the role of maternal programming under fluctuating predation risk. Ecology 91:2983-2994

Silverin B (1998) Behavioural and hormonal responses of the pied flycatcher to environmental stressors. Anim Behav 55:1411-1420

Smith PA, Tulp I, Schekkerman H, Gilchrist HG, Forbes MR (2012) Shorebird incubation behaviour and its influence on the risk of nest predation. Anim Behav 84:835-842

Travers M, Clinchy M, Zanette L, Boonstra R, Williams TD (2010) Indirect predator effects on clutch size and the cost of egg production. Ecol Lett 13:980-988

Vince MA (1969) Embryonic communication, respiration and the synchronization of hatching. In: Hinde RA (ed) Bird vocalizations. Cambridge University Press, Cambridge, pp 233-260

Wang JM, Beissinger SR (2009) Variation in the onset of incubation and its influence on avian hatching success and asynchrony. Anim Behav 78:601-613

Zanette LY, White AF, Allen MC, Clinchy M (2011) Perceived predation risk reduces the number of offspring songbirds produce per year. Science 334:1398-1401 